\title{
Investigation on Microstrip Filters with CSRR Defected Ground Structure
}

\author{
Arjun Kumar ${ }^{1}$, Ramesh Patel $^{2}$, M.V. Kartikeyan ${ }^{1}$ \\ ${ }^{1}$ Department of Electronics and Communication Engineering, Indian Institute of Technology Roorkee, India \\ ${ }^{2}$ School of Electrical Engineering, Ulsan National Institute of Science and Technology, South Korea \\ *corresponding author, E-mail: akdec.iitr@gmail.com
}

\begin{abstract}
This paper consists the design studies of complementary split ring resonator (CSRR) defected ground structure (DGS) microstrip filter with low insertion loss in the passband and high rejection in stopband with a comparison of various CSRR-DGS structure has been proposed. Various parameters of microstrip filters have been studied with CSRR-DGS such as roll off rate, bandwidth, effective inductance and capacitance. On the basis of these studies, microstrip low-pass, bandpass and dual-band bandstop filters have been designed and realized with enhanced properties of filters.
\end{abstract}

\section{Introduction}

In the era of fast changing technologies in wireless communication systems, the designers or researchers are forced to improve and enhance the performance of the microstrip components with miniaturized circuits. Defected ground structure (DGS) is well known technology that are used or using in many applications for miniaturizing the size of components. DGS have two main characteristics, one is slow-wave effect and another is bandstop properties. The slow-wave effect arises due to the defect in the ground plane of microstrip line. This slow-wave effect assists in size reduction of components [1-3]. In recent year, the lefthanded Metamaterial drew the attention of scientist, engineers and researchers in designing microwave components for high performance [4]. These metamaterials exhibits negative permittivity and permeability which result in a negative refraction. Metamatreial is not available in nature, it is artificially created material with negative permittivity or negative permeability [4-5]. The concept of metamaterial is used in complementary split ring resonator (CSRR) which is the combination of two split ring resonator [6]. In this paper, various shapes of complementary ring resonators are studied as defected ground structure for designing the microstrip filters [7-15]. All the CSRR-DGS structures have been simulated and compared with their frequency characteristics and also compared in terms of bandwidth, sensitivity and effective inductance and effective capacitance

\section{Comparison of different shapes of CSRR-DGS}

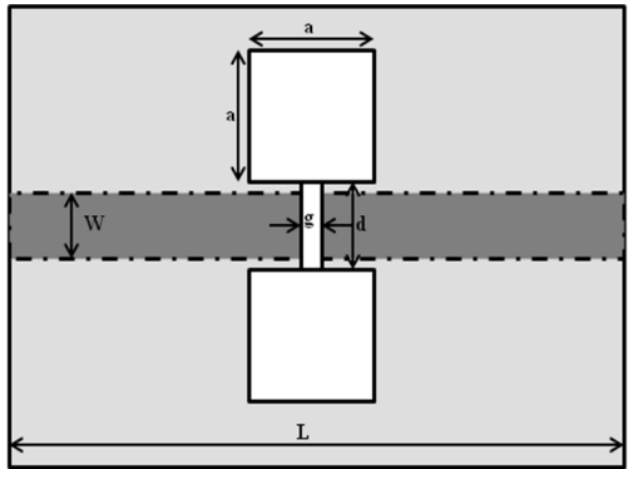

(a)

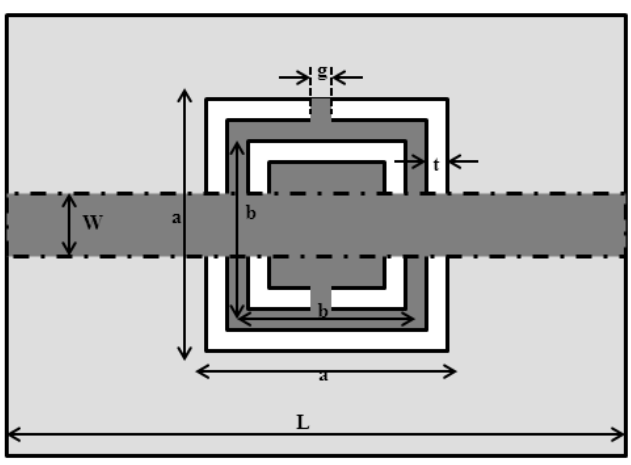

(b)

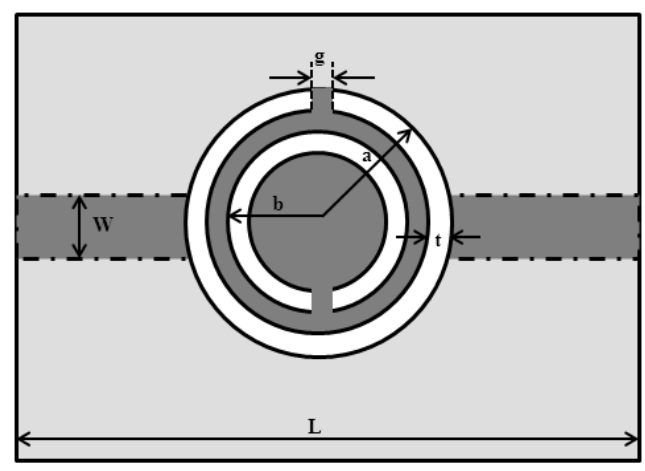

(c) 


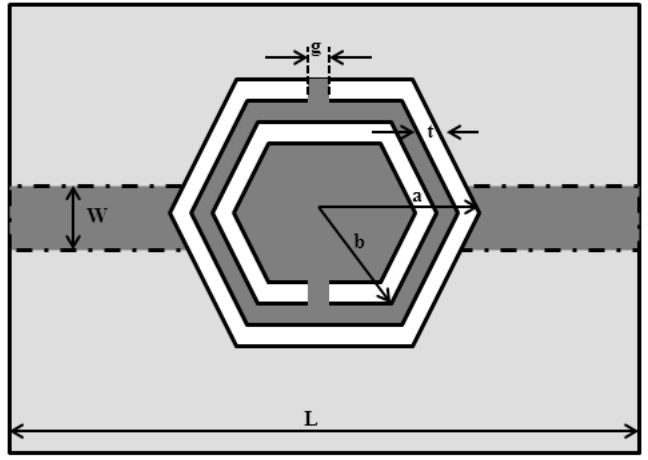

(d)

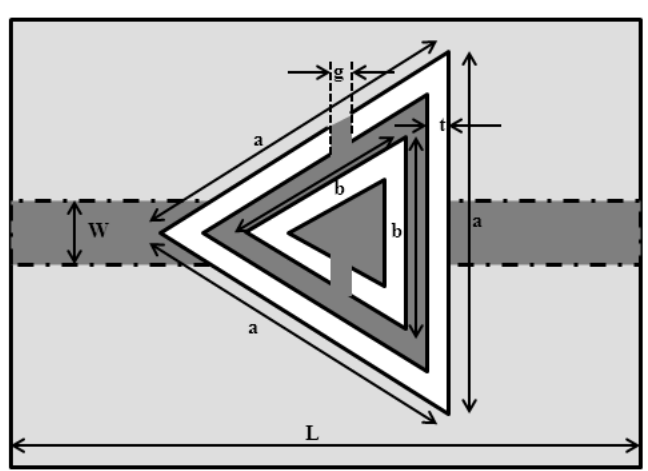

(e)

Fig.1 CSRR-DGS geometries with convention DGS: (a) Square DB-DGS (b) Square CSRR-DGS (c) Circular CSRRDGS (d) Hexagonal CSRR-DGS (e) Triangular CSRR-DGS

Fig.1 shows the geometries of various CSRR-DGS structures as well as convention dumbbell shaped DGS (DBDGS). For all the design configurations, the dielectric substrate is used FR4 with dielectric constant $\left(\varepsilon_{\mathrm{r}}\right) 4.4$ and loss tangent $(\tan \delta)$ is 0.0024 . The height of the substrate $(\mathrm{h})$ is $1.524 \mathrm{~mm}$ and the thickness of the conductor is $0.07 \mathrm{~mm}$. All the CSRR-DGS patterns have been created in the ground plane of $50 \Omega$, quarter wavelength $(\lambda / 4)$ microstrip line at 2.4 $\mathrm{GHz}$ and the area of this microstrip line is $17 \mathrm{X} 17 \mathrm{~mm}^{2}$ for all design configurations. The width (W) and length (L) of the microstrip line are $2.9 \mathrm{~mm}$ and $17 \mathrm{~mm}$.

Table 1. Dimensions of various DGS structures

\begin{tabular}{|c|c|c|c|c|c|}
\hline $\begin{array}{c}\text { Types of } \\
\text { DGS } \\
\text { structures }\end{array}$ & $\begin{array}{c}\mathrm{a} \\
(\mathrm{mm})\end{array}$ & $\begin{array}{c}\mathrm{b} \\
(\mathrm{mm})\end{array}$ & $\begin{array}{c}\mathrm{d} \\
(\mathrm{mm})\end{array}$ & $\begin{array}{c}\mathrm{g} \\
(\mathrm{mm})\end{array}$ & $\begin{array}{c}\mathrm{t} \\
(\mathrm{mm})\end{array}$ \\
\hline $\begin{array}{c}\text { Conventional } \\
\text { DB-DGS }\end{array}$ & 8.75 & - & 14 & 0.5 & - \\
\hline $\begin{array}{c}\text { Square } \\
\text { CSRR-DGS }\end{array}$ & 7.95 & 6.85 & - & 0.5 & 0.5 \\
\hline $\begin{array}{c}\text { Circular } \\
\text { CSRR-DGS }\end{array}$ & 4.65 & 3.65 & - & 0.5 & 0.5 \\
\hline $\begin{array}{c}\text { Hexagonal } \\
\text { CSRR-DGS }\end{array}$ & 4.91 & 3.91 & - & 0.5 & 0.5 \\
\hline $\begin{array}{c}\text { Triangular } \\
\text { CSRR-DGS }\end{array}$ & 6.62 & 4.83 & - & 0.5 & 0.5 \\
\hline
\end{tabular}

2.1. Bandstop characteristics of microstrip line with various CSRR-DGS patterns

In Fig. 2, S-parameter simulations of various CSRR-DGS geometries have been shown as bandstop filtering characteristics. From the Fig. 2, it is clearly observing that triangular CSRR-DGS has better roll-off rate or sharpness as compared to others.

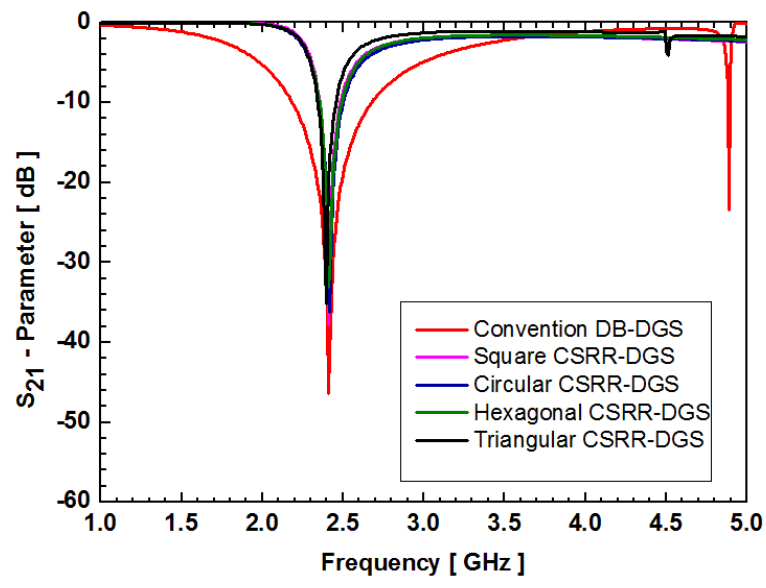

Fig. 2: Simulation results of microstrip bandstop filter with various CSRR-DGS patterns

All the simulations have been carried out keeping the resonant frequency constant. In all the case the resonant frequency is constant with variation in $3-\mathrm{dB}$ cutoff frequencies. In all design configurations, area of the structures is kept fix $17 \times 17 \mathrm{~mm}^{2}$. For conventional dumbbell-shaped DGS (DB-DGS) has large bandwidth but poor roll-off rate as compared to CSRR-DGS. In all the CSRR-DGS configuration sharpness of the filter is almost same except in triangular because in triangular CSRR-DGS, the current path is larger than other CSRR-DGS. So due to this extra-large path the slow wave effect will be more in triangular CSRR-DGS as compared to others.

\subsection{Analysis of various CSRR-DGS as bandstop filter}

A comparative performance of the microstrip bandstop filter with various CSRR-DGS structures have been shown in Table 2. It is clearly observed that the selectivity of triangular CSRR-DGS bandstop filter is higher than the other CSRR-DGS structures. The bandwidth of this triangular CSRR-DGS are narrow with high Q-factor as compared to other CSRR-DGS structure.

The parameters shown in Table 2, like roll-off rate, bandwidth, quality factor $(\mathrm{Q})$ and selectivity of the filter can be extracted using the expressions given below [8][10]:

Roll-off rate $=\frac{f_{c l}}{f_{o}}$

Bandwidth $(B W)=f_{u l}-f_{c l}$

Quality Factor $(Q)=f_{o} / B W$ 
Table 2: Comparison of performance of microstrip bandstop filter with various CSRR-DGS geometries

\begin{tabular}{|l|c|c|c|c|c|c|c|c|}
\hline $\begin{array}{c}\text { Type of } \\
\text { DGS } \\
\text { Structures }\end{array}$ & $\begin{array}{c}\text { Resonant } \\
f_{o}(\mathrm{GHz})\end{array}$ & $\begin{array}{c}\text { Lower 3- } \\
\text { dB Cut-off } \\
\text { Frequency } \\
f_{c l}(\mathrm{GHz})\end{array}$ & $\begin{array}{c}\text { Upper } \\
\text { 3-dB Cut- } \\
\text { off } \\
\text { Frequency } \\
f_{u l}(\mathrm{GHz})\end{array}$ & $\begin{array}{c}\text { Roll- } \\
\text { off } \\
\text { Factor } \\
\left(f_{c l} / f_{o}\right)\end{array}$ & $\begin{array}{c}\text { Bandwidth } \\
(B W) \text { of } \\
\text { filter } \\
(\mathrm{GHz})\end{array}$ & $\begin{array}{c}\text { Quality } \\
\text { Factor } \\
(\mathrm{Q}) \\
\left(f_{o} / B W\right)\end{array}$ & $\begin{array}{c}20-\mathrm{dB} \\
\text { stopband } \\
\text { frequency } \\
\left(f_{s}\right)\end{array}$ & $\begin{array}{c}\text { Selectivity } \\
(\xi) \text { of filter } \\
(\mathrm{dB} / \mathrm{GHz})\end{array}$ \\
\hline $\begin{array}{l}\text { Conv. DB- } \\
\text { DGS }\end{array}$ & 2.4 & 1.83 & 3.28 & 0.76 & 1.43 & 1.67 & 2.34 & 33.3 \\
\hline $\begin{array}{l}\text { Square } \\
\text { CSRR- } \\
\text { DGS }\end{array}$ & 2.4 & 2.27 & 2.71 & 0.94 & 0.44 & 5.47 & 2.40 & 121.4 \\
\hline $\begin{array}{l}\text { Circular } \\
\text { CSRR- } \\
\text { DGS }\end{array}$ & 2.4 & 2.26 & 2.77 & 0.94 & 0.52 & 4.63 & 2.40 & 121.4 \\
\hline $\begin{array}{l}\text { Hexagonal } \\
\text { CSRR- } \\
\text { DGS }\end{array}$ & 2.4 & 2.26 & 2.72 & 0.94 & 0.46 & 5.22 & 2.39 & 130.7 \\
\hline $\begin{array}{l}\text { Triangular } \\
\text { CSRR- } \\
\text { DGS }\end{array}$ & 2.4 & 2.30 & 2.60 & 0.96 & 0.30 & 8.00 & 2.38 & 212.5 \\
\hline
\end{tabular}

$\operatorname{Selectivity~}(\xi)=\frac{\alpha_{\min }-\alpha_{\max }}{f_{s}-f_{c l}}$

Where $\alpha_{\min }, \alpha_{\max }$, are the $20-\mathrm{dB}$ and $3-\mathrm{dB}$ attenuation respectively, whereas $f_{s}, f_{c l}, f_{u l}$ are the stop frequency at $20-\mathrm{dB}$ attenuation and $3-\mathrm{dB}$ lower cutoff and upper cutoff frequencies. The unit of selectivity $(\xi)$ is $\mathrm{dB} / \mathrm{GHz}$. On the basis of filter performance in Table 2 , a triangular shaped CSRR-DGS is well suited for bandstop, bandpass, low pass and dual-band bandstop filters.

\section{Design and Realization of Low Pass Filter with Triangular CSRR-DGS}

On the basis of the above analysis of triangular CSRRDGS, a low pass filter has been proposed for L-band application with enhanced sharpness and low insertion loss in the passband (up to $3.2 \mathrm{GHz}$ ) and high rejection in stopband with insertion loss in the pass band (below 15$\mathrm{dB}$ attenuation up to $7.5 \mathrm{GHz}$ ).

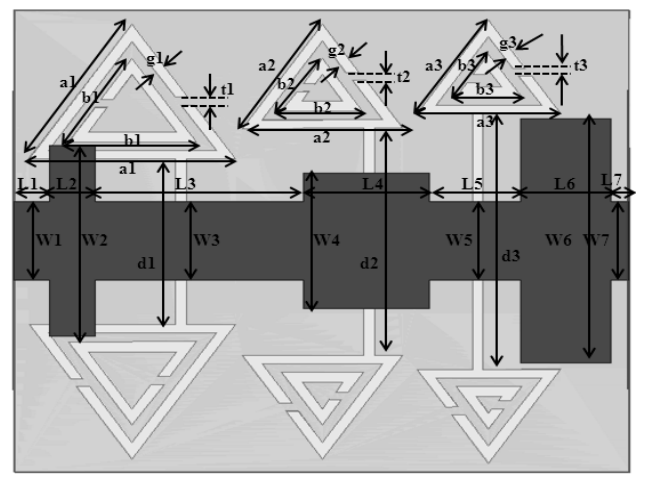

Fig. 3: Proposed design for microstrip low pass filter with triangular CSRR-DGS
In Fig. 3, a proposed microstrip low pass filter has been shown with the triangular CSRR-DGS array using stepped impedance in conducting strip. The design specifications and goals for this filter are substrate FR4 Epoxy $\left(\varepsilon_{\mathrm{r}}\right)=4.4$, height of substrate $(\mathrm{h})=1.524 \mathrm{~mm}$, thickness of conductor $(\mathrm{n})=0.07 \mathrm{~mm}$, loss tangent $(\tan \delta)$ $=0.0024,3-\mathrm{dB}$ cutoff frequency $\left(\mathrm{f}_{\mathrm{c}}\right)=3.2 \mathrm{GHz}$ with insertion loss of $0.5 \mathrm{~dB}$ and more than $15 \mathrm{~dB}$ rejection in stopband $(3.4 \mathrm{GHz}$ to $7.5 \mathrm{GHz})$. The size of the filter has been kept fix $17 \times 17 \mathrm{~mm}^{2}$. In Fig. 3 , the dimensions are $\mathrm{L} 1=1 \mathrm{~mm}, \mathrm{~L} 2=1.25 \mathrm{~mm}, \mathrm{~L} 3=6 \mathrm{~mm}, \mathrm{~L} 4=3.5 \mathrm{~mm}, \mathrm{~L} 5$ $=\mathrm{L} 6=2.5 \mathrm{~mm}, \mathrm{~L} 7=0.25 \mathrm{~mm}, \mathrm{~W} 1=\mathrm{W} 3=\mathrm{W} 5=\mathrm{W} 7=$ $2.9 \mathrm{~mm}, \mathrm{~W} 2=7 \mathrm{~mm}, \mathrm{~W} 4=5 \mathrm{~mm}, \mathrm{~W} 6=9 \mathrm{~mm}, \mathrm{a} 1=3.3$ $\mathrm{mm}$, a $2=2.3 \mathrm{~mm}, \mathrm{a} 3=2.55 \mathrm{~mm}, \mathrm{~b} 1=2.68 \mathrm{~mm}, \mathrm{~b} 2=$ $1.68, \mathrm{~b} 3=1.93 \mathrm{~mm}, \mathrm{~g} 1=0.3 \mathrm{~mm}, \mathrm{~d} 1=6.15 \mathrm{~mm}, \mathrm{~d} 2=$ $8.45 \mathrm{~mm}$ and $\mathrm{d} 3=9.65 \mathrm{~mm}$.

\subsection{Fabrication and Measurement}

The proposed design has been fabricated and the layouts of fabricated design have been shown in Fig. 4, with bottom view and top view of filter.

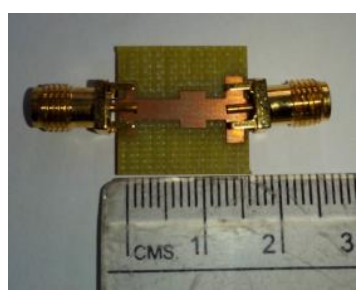

(a)

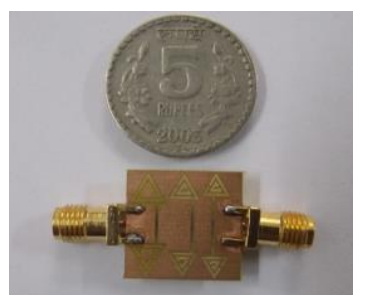

(b)
Fig. 4: Fabricated layout of proposed microstrip low pass filter with triangular CSRR-DGS: (a) top view (b) bottom view 
After the fabrication the frequency characteristics of fabricated filter are measured in the VNA. Fig. 5 shows the S-parameters of simulated and measured of proposed microstrip low pass filter. From the Fig. 5, it can be observed that after the fabrication, insertion loss is more with more ripples in the pass band



Fig. 5: Simulation and measured results of microstrip low pass filter

This insertion loss is $0.9 \mathrm{~dB}$ in the passband but high rejection in stop band with wide stopband. In the measurement ripple is more due to the noise in VNA cable but the pattern of measured result is almost same. The $3-\mathrm{dB}$ cutoff frequency $(3.2 \mathrm{GHz})$ is same for both simulated and measured results. In the measurement results more than $15 \mathrm{~dB}$ attenuation is achieved from 3.8 $\mathrm{GHz}$ to $7.8 \mathrm{GHz}$ whereas in simulated result, it is 3.6 $\mathrm{GHz}$ to $7.8 \mathrm{GHz}$ which is good in the agreement.

\section{Design and Realization of Dual-Band Bandstop Filter using Triangular CSRR-DGS}

For designing the dual-band band stop filter we use the same triangular CSRR DGS topology in dumbbell shaped pattern. In Fig. 6, two triangular CSRR-DGS connected to a slot which is nothing but a dumbbell shaped pattern as conventional dumbbell shape DGS. But the main key features of this proposed design is to get dual band properties along with an appropriate size reduction, which is not achievable in conventional dumbbell shaped DGS. These two triangular CSRR DGS are asymmetrical in dimensions so they are resonating at two different frequency. Resonator-1 is resonating at the frequency $3.5 \mathrm{GHz}$ and resonator- 2 is resonating the frequency at $5.7 \mathrm{GHz}$. The CSRR structure is composed of two concentric metallic slot rings, each interrupted by a small gap at its opposite sides. The gap strongly decreases the resonant frequency of the structure, which make the size of the CSRR only a tenth of the corresponding resonant wavelength. The thickness of the gap is also responsible for widening the bandwidth. The CSRR shows strong electric response at its resonant frequency when driven by an external time-varying electric field parallel to ring axis. The proposed design is based on the anisotropic property of the complimentary split ring resonator. The CSRR is an anisotropic structure for asymmetric gaps, thus the orientation of the CSRR relative to incident wave must be carefully controlled. When the gaps of the CSRR oriented parallel to the wave propagating direction, it will render dual resonant frequency waves. Here dumbbell shape triangular CSRR is used only for the size reduction [1]

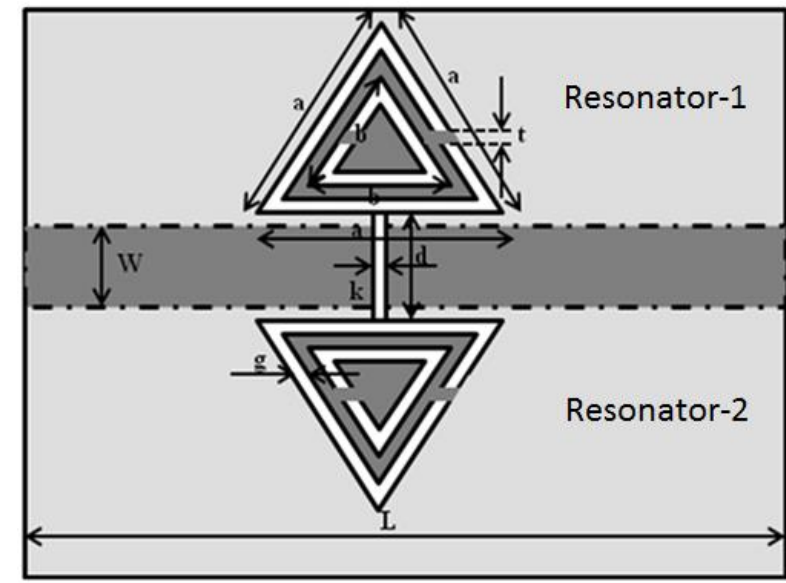

Fig. 6: Proposed design of dual-band microstrip bandstop filter with triangular CSRR-DGS

This dual-band microstrip bandstop filter is designed at two resonant frequencies which are $3.5 \mathrm{GHz}$ and $5.7 \mathrm{GHz}$ respectively. In this proposed design the same dielectric material is used with the same specification with the above designed filters using the same $50 \Omega$ microstrip line. The dimensions of this proposed dual band bandstop filter are given as: resonator- $1(\mathrm{a}=3.5 \mathrm{~mm}, \mathrm{~b}=2.8 \mathrm{~mm}$, $\mathrm{g}=0.35 \mathrm{~mm}, \mathrm{t}=0.3 \mathrm{~mm}, \mathrm{~d}=12 \mathrm{~mm}$ and $\mathrm{k}=0.3 \mathrm{~mm})$ and resonator $-2(\mathrm{a}=3.3 \mathrm{~mm}, \mathrm{~b}=2.6 \mathrm{~mm}, \mathrm{t}=0.3 \mathrm{~mm}, \mathrm{k}=$ $0.3 \mathrm{~mm}$ )

\subsection{Fabrication and Measurement}

The proposed dual-band microstrip bandstop filter has been fabricated and the layouts of fabricated design have been shown in Fig. 7, with bottom view and top view of filter. Fig. 7 (a) is the top layer of the microstrip bandstop filter and Fig. 7 (b) is the bottom layer of the fabricated microstrip bandstop filter.

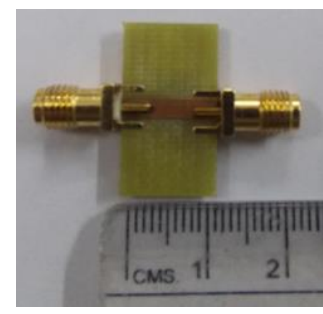

(a)

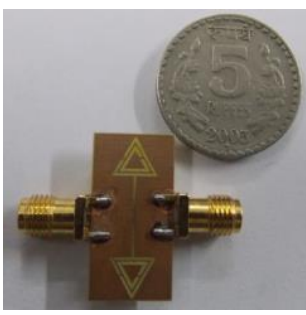

(b)
Fig. 7: Fabricated layout of proposed dual-band microstrip bandstop filter with triangular CSRR-DGS: (a) top view (b) bottom view 
After the fabrication, the frequency characteristics of fabricated design are measured in the VNA. In the Fig. 8 frequency characteristics of measured and simulated are shown. In the simulated frequency characteristics, high rejection at resonant frequencies (more than $40 \mathrm{~dB}$ return loss at $3.8 \mathrm{GHz}$ and $5.7 \mathrm{GHz}$ respectively).

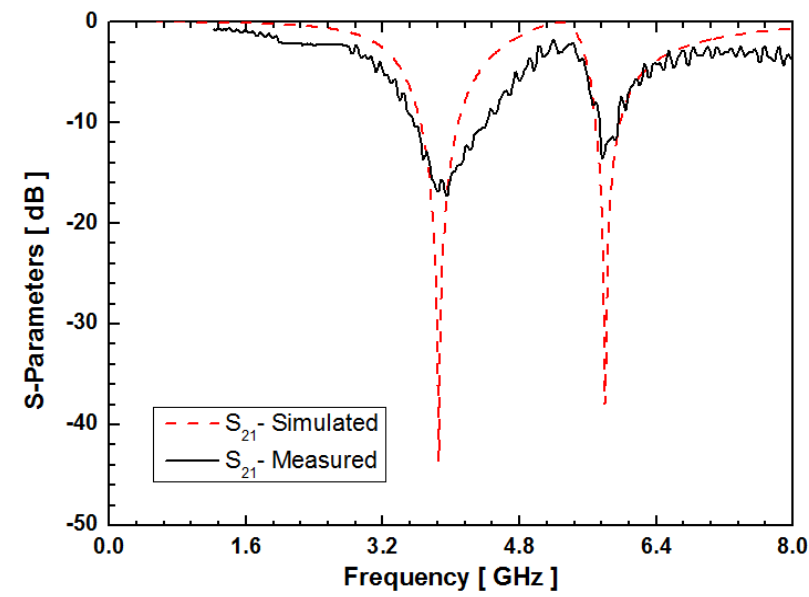

Fig. 8: Simulation and measured results of dual-band microstrip bandstop filter

But in measurement the return loss $16 \mathrm{~dB}$ at $3.8 \mathrm{GHz}$ and $14 \mathrm{~dB}$ at $5.7 \mathrm{GHz}$ which is less as compare to a simulated one whereas the resonance frequencies are almost same as. The 3-dB bandwidth of a bandstop filter for dual-band are $1.4 \mathrm{GHz}$ and $1.6 \mathrm{GHz}$ the measured resonance frequencies are well in agreement with simulated results and return loss is also in acceptable limits.

\section{Design and Realization of Bandpass Filter using Triangular CSRR-DGS}

In this section a microstrip bandpass filter is proposed as shown in Fig. 9 with $0.3 \mathrm{~dB}$ insertion loss in the passband and high more than $15 \mathrm{~dB}$ attenuation in stopband and the center frequency of this proposed filter is $4.0 \mathrm{GHz}$. This filter is also designed using triangular CSRR-DGS topology. The bandwidth of this filter is $300 \mathrm{MHz}$. In this proposed design, a stepped impedance method is used with a slot in the conducting strip which gives the series capacitance which is responsible for bandpass characteristics [2]. The reason to choose stepped impedance method is to achieve low pass characteristics and slot gap in strip gives the high pass characteristic so by the combination of both give the bandpass characteristics. The design specifications for this filter are substrate FR4 Epoxy $\left(\varepsilon_{\mathrm{r}}\right)=4.4$, height of substrate $(\mathrm{h})=$ $1.524 \mathrm{~mm}$, thickness of conductor $(\mathrm{n})=0.07 \mathrm{~mm}$, loss $\operatorname{tangent}(\tan \delta)=0.0024$. The size of the filter has been kept fix $17 \times 17 \mathrm{~mm}^{2}$. In Fig. 12 , the dimensions are L1 $=1 \mathrm{~mm}, \mathrm{~L} 2=1.25 \mathrm{~mm}, \mathrm{~L} 3=6 \mathrm{~mm}, \mathrm{~L} 4=3.5 \mathrm{~mm}, \mathrm{~L} 5=$ $\mathrm{L} 6=2.5 \mathrm{~mm}, \mathrm{~L} 7=0.25 \mathrm{~mm}, \mathrm{~W} 1=\mathrm{W} 3=\mathrm{W} 5=\mathrm{W} 7=2.9$ $\mathrm{mm}, \mathrm{W} 2=7 \mathrm{~mm}, \mathrm{~W} 4=5 \mathrm{~mm}, \mathrm{~W} 6=9 \mathrm{~mm}, \mathrm{a} 1=3.3$ $\mathrm{mm}$, a $2=2.3 \mathrm{~mm}, \mathrm{a} 3=2.55 \mathrm{~mm}, \mathrm{~b} 1=2.68 \mathrm{~mm}, \mathrm{~b} 2=$
$1.68, \mathrm{~b} 3=1.93 \mathrm{~mm}, \mathrm{~g} 1=0.3 \mathrm{~mm}, \mathrm{~d} 1=6.15 \mathrm{~mm}, \mathrm{~d} 2=$ $8.45 \mathrm{~mm}$ and $\mathrm{d} 3=9.65 \mathrm{~mm}, \mathrm{P}=0.3 \mathrm{~mm}, \mathrm{k} 1=\mathrm{k} 2=\mathrm{k} 3=$ $0.5 \mathrm{~mm}$.

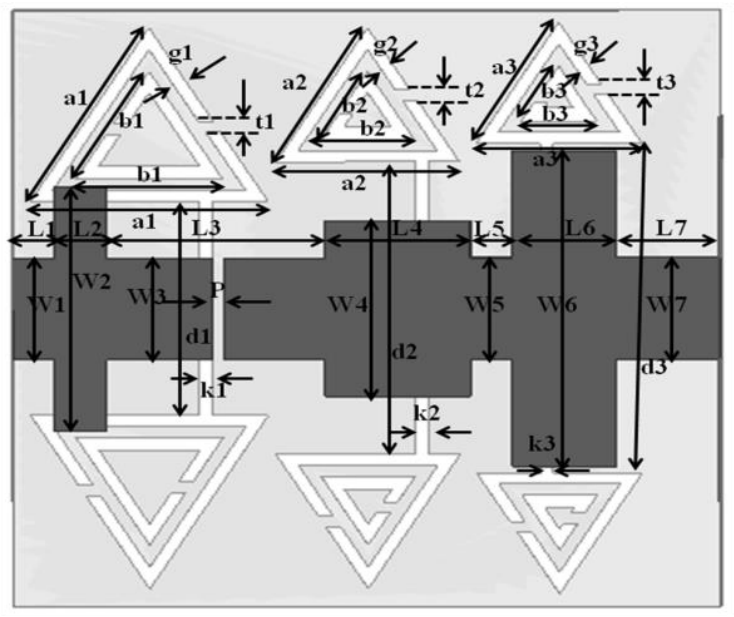

Fig. 9: Proposed design for microstrip low pass filter with triangular CSRR-DGS

\subsection{Fabrication and Measurement}

The proposed microstrip bandpass filter has been fabricated and the layouts of fabricated design have been shown in Fig. 15, with bottom view and top view of filter. Fig. 10 (a) is the top layer of the microstrip bandstop filter and Fig. 10 (b) is the bottom layer of the fabricated microstrip bandpass filter.



(a)

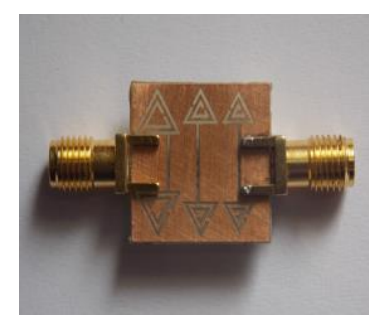

(b)
Fig. 10: Fabricated layout of proposed microstrip bandpass filter with triangular CSRR-DGS: (a) top view (b) bottom view

After the fabrication, the frequency characteristics of fabricated design are measured in the VNA. In the Fig. 11 frequency characteristics of measured and simulated are shown. In the simulated frequency characteristics, 3-dB bandwidth is $300 \mathrm{MHz}$. The upper and lower 3-dB cutoff frequencies are $4.2 \mathrm{GHz}$ and $3.9 \mathrm{GHz}$ respectively and the insertion loss in passband $0.3 \mathrm{~dB}$ at center frequency $4 \mathrm{GHz}$. In measurement the insertion $1.8 \mathrm{~dB}$ which is more as compared to a simulated one whereas the resonant frequency is almost same as. The 3-dB bandwidth of a bandpass filter is almost $300 \mathrm{MHz}$. In all respect the simulated results are quite in resembles with the measured results after the fabrication for the proposed bandpass filter. 


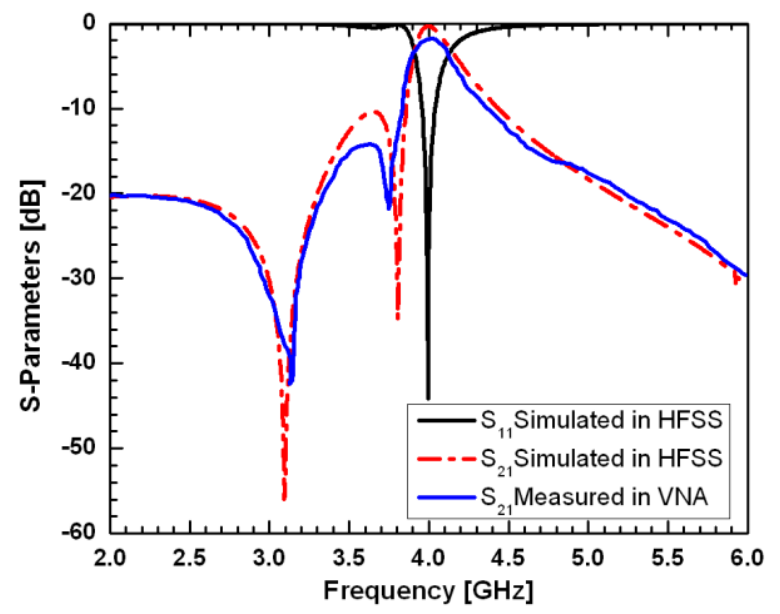

Fig. 11: Simulation and measured results of microstrip bandpass filter

\section{Conclusions}

In this paper, investigation on microstrip filters with various CSRR defected ground structures (low insertion loss in pass band \& high rejection in stop band) has been proposed. Various investigating parameters of microstrip filters such as roll off rate, bandwidth, effective inductance and capacitance have been studied with different configurations of CSRR-DGS. Then after triangular CSRR-DGS configuration is used to design dual band, low pass and band pass filters due to better roll-off rate, higher selectivity and high Q-factor as compared to other CSRR configurations. The stepped impedance method is used to achieve low pass characteristics (low pass filter design) and slot gap in strip gives the high pass characteristic so by the combination of both give the bandpass characteristics (bandpass filter design). The anisotropic property of the complimentary split ring resonator is used to get dual band characteristics and dumbbell shaped triangular CSRR-DGS are used to get size reduction. Simulation and measurement results of these all configuration are provided

\section{References}

[1]. D. Ahn, J.S. Park, C.S. Kim, J. Kim, Y. Qian, and T. Itoh, "A design of the low-pass filter using the novel microstrip defected ground structure," IEEE Transactions on Microwave Theory and Techniques., Vol. 49, No. 1, 86-91, Jan. 2001.

[2]. J.S.Lim, C.S. Kim, Y.T. Lee, D.Ahn and S.Nam, "Design of low pass filters using defected ground structure and compensated microstrip line," Electronics Lett., Vol. 38, pp. 1357-1358, October, 2002.

[3]. Arjun Kumar, and M.V. Kartikeyan, "Microstrip Filter with defected ground structure: A close perspective," International Journal of Microwave and Wireless Technologies, Vol. 5, No.5, pp.589602, October, 2013.
[4]. Bayindir, M.K.Aydin, E. Ozbay, P. Markos, and C.M. Soukoulis, "Transmission properties of composite metamaterials in free space," Applied Physics Letters, Vol.81, pp. 120-122, 2002.

[5]. C.D. Moss, T.M. Grzegorczyk, Y.Zhang, and J.A. Kong, "Numerical studies of left handed materials," Progress In Electromagnetics Research, PIER, Vol.35, pp.315-334, 2002.

[6]. H. Bahrami, and M. Hakkak, "Analysis and design of highly compact bandpass waveguide filter utilizing complementary split ring resonators (CSRR)," Progress In Electromagnetics Research, PIER, Vol.80, pp.107-122, 2008.

[7]. F.Falcone, T. Lopetegi, J.D. Baena, R. Marques, F. Martin, and M. Sorolla, "Effective negative- $\varepsilon$ stopband microstrip lines based on complementary split ring resonators," IEEE Microw. Wireless Components Lett., Vol.14, No.6, pp.280-282, 2004.

[8]. A. Ali, and Z. Hu, "Negative permittivity metamaterial microstrip binomial low-pass filter with sharp cut-off and reduced size," IET Microw. Antennas Propag., Vol.2, No.1, pp.15-18, 2008.

[9]. H.Zhang, Y.Q. Li, X. Chen, Y.Q. Fu, and N.C. Yuan, "Design of circular polarization microstrip patch antennas with complementary split ring resonator," IET Microw. Antennas Propag. Vol.3, No.8, pp.1186-1190, 2009.

[10]. A. Kumar, J. Malik, and M.V.Kartikeyan, “A comparative study of microstrip bandstop filters loaded with various dumbbell shaped defected ground structure," International Journal of Microwave and Optical Technology, Vol.8, No.2, pp.53-60, 2013.

[11]. C. Li, and F. Li, "Characterization and modeling of a microstrip line loaded with complementary split-ring resonators (CSRRs) and its application to high pass filters", J. Phys. D: Appl. Phys., Vol. 40, pp.3780-3787, 2007.

[12]. Y. Xu, and A. Alphones, "Novel DGS-CSRRbased microstrip low pass filter with ultra wide suppression", Int. J. Ultra Wideband Communications and Systems, Vol. 1, No. 3, pp. 169-172, 2010.

[13]. S. S. Karthikeyan, and R. S. Kshetrimayum, "Harmonic suppression of parallel coupled microstrip line bandpass filter using CSRR", Progress In Electromagnetics Research Letters, Vol. 7, 193-201, 2009.

[14]. Xiao,J.-K.,S.-W. Ma,S. Zhang,and Y. Li,“Novel compact split ring stepped-impedance resonator (SIR) bandpass filters with transmission zeros," Journal of Electromagnetic Waves and Applications, Vol. 21, No. 3, pp. 329-339, 2007.

[15]. J. Zhang, B. Cui, and X. W. Sun, "Sharp rejection Low pass filter with controllable transmission zero using complementary split ring resonator (CSRR)," Progress In Electromagnetics Research, PIER, Vol. 69, pp. 219-226, 2007. 